\title{
HSI Newsletter 01/2019
}

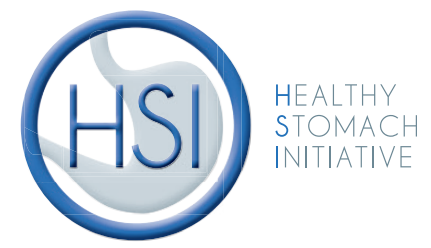

Dear Members of the Healthy Stomach Initiative,

Thanks to all contributors for an exciting meeting at the DDW in San Diego. Please see below updates on current issues, recent events and excellent studies that are the heart of this initiative.

We also would like to invite you to celebrate the second WORLD STOMACH DAY on October 2nd, 2019. Please let us know if you plan any activities, events or press releases for this important day and don't hesitate to get in touch if you need any support. In order to share more details, we kindly ask all to submit their ideas to the HSI office at office@d-seurope.com. Our next HSI meeting during the UEGW nears and it would be welcomed to include all activities during the presentations.

Thanks to our sponsors and supporters! We appreciate your support and we are looking forward to growing the HSI together with you Please contact us (office@d-s-europe.com) if you would like to add or suggest any content for the upcoming HSI meeting and/or the upcoming newsletters.

\section{SAVE THE DATE}

UEGW 2019 Barcelona

Please join us on October 20th from 10 am to 12 noon

for the annual HSI meeting

If you would like to present, kindly submit your info to office@d-s-europe.com

Your HSI Team

\section{Update and Summary HSI Meeting DDW 2019}

\section{HSI @ Digestive Disease Week 2019. San Diego, USA}

Thank you again to all who contributed to this inspiring update on HSI activities:

Emad El-Omar contributed with a perspective of upcoming landmark publications including the new Kyoto Consensus on neoplasias of the gastro-oesophageal junction involving new insights in pathomechanism, diagnostic assessment and treatment, as well as the report of the results of a large Taiwanese study on the short- and long-term effect of $H$. pylori eradication on the gut microbiota. Richard Hunt reported on the WGO initiatives in prevention of gastrointestinal cancers and possible links with the HSI for the World Stomach Day. Peter Malfertheiner presented an overview on the rapidly evolving field of gastric microbiota research, in particular pointing out the dominating effect of $H$. pylori when present as well as the influence of the stomach microenvironment on carcinogenesis. We were updated on national activities to further promote or establish gastric cancer screening strategies in Taiwan, Brazil, Malaysia and Latvia by JM. Liou, L. Coelho, Y. Lee \& M. Leja. From Croatia, Z. Krznaric and D. Stimac presented highlights on the impact of nutrition on digestive health and delivered a short update of the recent PGC "Nutrition Challenges in GI diseases". Per Hellstroem shared details about the HELP-SWEDEHEART project and Francis Megraud informed about new tools for antimicrobial susceptibility testing and presented his ongoing survey on $H$. pylori resistance to antibiotics across Europe. R. Malekzadeh, Iran was not able to attend due to the travel ban for Iranian citizens. He provided details on his project, which can also be found on the HSI website. 


\section{HSI 2019/2020 - endorsed events and activities}

Details and presentations can be found on the Healthy Stomach Initiative website www.hsinitiative.org

10th Asian Pacific Topic Conference, September 29-29, 2019 in Kaohsiung, Taiwan - Screening and eradication of Helicobacter pylori for gastric cancer preventionunresolved problems.

We would like to invite members of the HSI to submit abstracts to APTC https://www.2019aptc.org/).

The deadline will be extended to July 20, 2019. Presenters of accepted abstracts will receive free registration. We offer travel grants (USD 500 for foreigners) to the presenters of the top 5 abstracts. For colleagues who are not able to attend the conference in Kaohsiung, online viewing of the conference will be available (https://www.2019aptc.org/). Please contact the HSI office for your access code.

\section{Asian Pacific DDW 2020, Kuala Lumpur, Malaysia}

Similarly, we also would take up the opportunity to invite already to the Asian Pacific DDW 2020 in Kuala Lumpur, Malaysia, during which a special HIS event will be hosted. http://www.apdw2020.org/

\section{The HELP-SWEDEHEART Study}

Per Hellström introduced us to the HELP-SWEDEHEART study that investigates the effect of $H$. pylori screen-and-treat in patients with recent myocardial infarction reduces the risk for upper GI bleeds and therefore the need for re-hospitalisation. The trial will be a cluster randomized, registrybased clinical trial using the Swedish Web System for Enhancement and Development of Evidence-based Care in Heart Disease Evaluated According to Recommended Therapies (SWEDEHEART) and other national registries as trial platform for patient enrolment and data collection. Thus far, more than 20,000 patients have been recruited.

ENIGMA I and ENIGMA II, in collaboration with IARC Reza Malekzadeh provides to us an update on the ENIGMA projects, which are run in collaboration with IARC, Lyon.

ENIGMA I is a population-based survey analysing the prevalence of $H$. pylori infection in high incidence areas for gastric cancer, with focus on assessment of the effect of both host and bacterial factors on gastric cancer incidence and molecular phenotype. The study population in each site will include a population-based sample of 700 individuals 1 to 69 years old stratified by gender and 5 -year age groups.

ENIGMA II set its focus on premalignant lesions and investigates the prevalence and determinants of gastric premalignant conditions in high and low GC risk areas. To expand ecological comparisons of ENIGMA I between high and low risk areas, this will also include markers that can be obtained by endoscopic biopsies. All the ENIGMA I participants who are older than 40 years and who have $H$. pylori test results will be invited to participate in ENIGMA II.

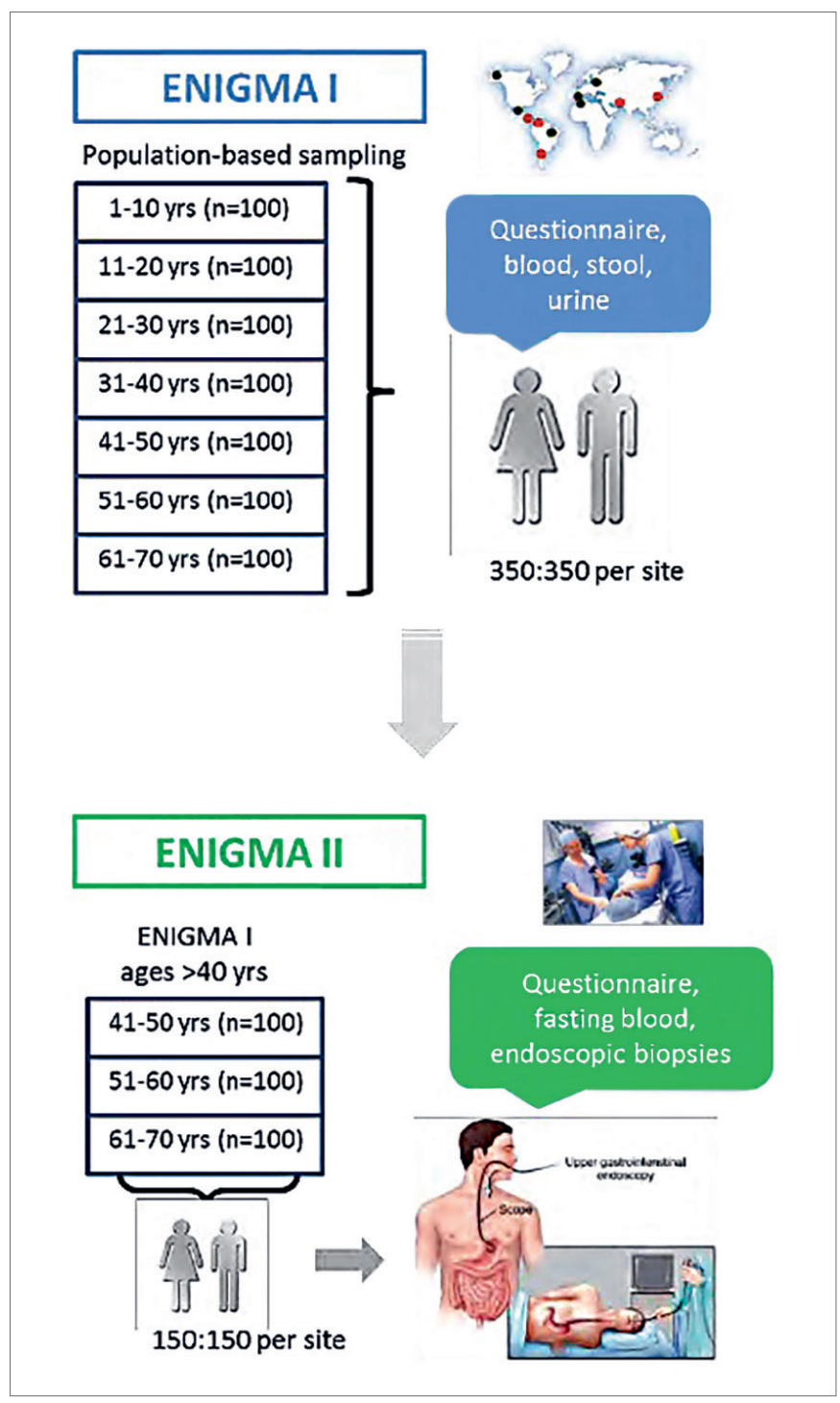

The Ardabil Trial - Effect of low-dose Aspirin on Incidence and Mortality of Gastric Cancer in the Northwest of Iran Reza Malekzadeh also introduces the Ardabil trial, the first population-based study with the objective of gastric cancer prevention using Aspirin in Ardabil in which a high incidence of GC has been reported. The result of this study can be used as a model in GC chemoprevention for national and even global levels. Plan is to recruit 18,000 participants of which 4950 have already been recruited. Interestingly, $70 \%$ of these were $\mathrm{H}$ pylori positive. Subjects are followed up for 12 weeks to determine complications. The long term follow up has been started after the 12 -week period and will continue for 10 years. During these 10 years, participants will be regularly contacted every year to determine outcomes and complications. Also at years 5 and 10 a repeat sampling will be done along with a short follow-up questionnaire. (IRCT201105082032N3) 


\section{Our "walk-in" stomach model needs a new home. PLEASE HELP!}

Our walk-in stomach model is looking for a new home. The current storage facility in Germany is not available any longer, hence we are in urgent need for a new storage or medium/long term exhibition space. The best option would be setting up the model in a department or hospital, in schools or medical schools where it could stimulate young minds to get involved with gastric pathology and physiology. We are happy to arrange for the transport and set up of the stomach model if it can be a 12 months display. Please let us know if you have ideas!

\section{HSI - World Stomach Day}

Last year, we celebrated the first World Stomach Day on October 2nd, and we were able to report on some amazing activities organised across the globe. As intended by Prof. $\mathrm{Wu}$ from Taiwan who he initiated this date for a global stomach awareness day, we will continue and call for everyone to plan activities for the second WORLD STOMACH DAY on
October 2nd 2019. Please join this initiative on this day on which 37 years ago, Barry Marshall had first reported $H$. pylori. Let us know if you need any support and don't forget to send us any updates on activities held in your area. Pictures are welcome!

\section{A word from our supporters}

\section{BIOHIT HealthCare \\ Innovating for Health}

Biohit Oyj is a globally operating Finnish biotechnology company established in 1988. Biohit's mission is "Innovating for Health". Biohit is headquartered in Helsinki and has subsidiaries in Italy and the UK. Biohit's Series B share (BIOBV) is quoted on NASDAQ OMX Helsinki since 1999,
Small cap/Healthcare. Biohit has been a long-standing partner and promoter of the Healthy Stomach Initiative. Minna Maki introduced herself and Biohit during the HSI meeting in San Diego.

\section{KARGER}

Medical and Scientific Publishers

Publishers proudly supports the HSI.

Nicolas Vignon introduced himself and expressed continued interest to support the HSI. In addition, Karger edits and promotes the HSI newsletters. www.karger.com

\section{Digestive Gastro Inflammatory Diseases Intestinal Intestinal Diseases}


A global leader in the field of high quality in vitro diagnostics (IVD) testing. It has more than 50 years' accumulated experience in the conception, development, production and worldwide commercialization of robust IVD products. Today, Fujirebio's global presence includes offices in the United States, Latin America, Europe and Asia as well as a vast international distribution network. Fujirebio has a strong and long-lasting tradition of collaborating with experts in the worldwide clinical community in the development of high-quality routine and truly novel biomarkers that cover a variety of disease states. www.fujirebio-europe.com. T. Matysiak-Budnik kindly introduced Fujirebio as their representative was not able to be in SanDiego. Fujirebio is interested in finding collaborators for studies. In particular in Germany, UK, Spain and Italy. For more info, please contact:

Victor Ruiz, Email: victor.ruiz@fujirebio.com

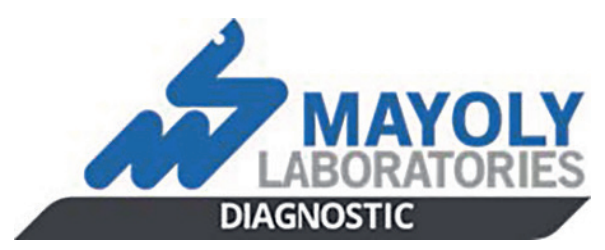

Mayoly Spindler is an independent French family-run pharmaceutical company, which has been growing for several decades. We have extensive expertise in gastroenterology, rheumatology, ENT, general medicine and consumer health solutions. With our own production facilities, we are able to control our industrial developments. Laboratory Mayoly Spindler aquired Kibion, a global leader in complete solutions for rapid reliable Urea Breath Tests for diagnosing the stomach ulcer bacterium Helicobacter pylori, in Sep 2016. This acquisition will strengthen both companies' globally and generate outstanding synergies. Kibion is now successfully integrated in the Mayoly Spindler Group. The company currently supplies test systems and high-quality instruments to institutions, hospitals and laboratories in more than 50 countries around the world. In addition, it continuously evaluates new business opportunities within its field of operations. Dr Marco Silvestric introduced Mayoly / Kibion and shared the vision of the company and their interest in the collaboration with the Healthy Stomach Initiative. 